\title{
Signal propagation related to the North Atlantic overturning
}

\author{
J. Getzlaff, C. W. Böning, C. Eden, and A. Biastoch \\ Leibniz-Institut für Meereswissenschaften an der Universität Kiel (IFM-GEOMAR), Kiel, Germany
}

Received 13 July 2004; revised 28 February 2005; accepted 22 March 2005; published 3 May 2005.

[1] Changes of the meridional overturning circulation (MOC) due to surface heat flux variability related to the North Atlantic Oscillation (NAO) are analyzed in various ocean models, i.e., eddying and non-eddying cases. A prime signature of the forcing is variability of the winter-time convection in the Labrador Sea. The associated changes in the strength of the MOC near the subpolar front $\left(45^{\circ} \mathrm{N}\right)$ are closely related to the NAO-index, leading MOC anomalies by about 2-3 years in both the eddying and non-eddying simulation. Further south the speed of the meridional signal propagation depends on model resolution. With lower resolution (non-eddying case, $4 / 3^{\circ}$ resolution) the $\mathrm{MOC}$ signal propagates equatorward with a mean speed of about $0.6 \mathrm{~cm} / \mathrm{s}$, similar as spreading rates of passive tracer anomalies. Eddy-permitting experiments $\left(1 / 3^{\circ}\right)$ show a significantly faster propagation, with speeds corresponding to boundary waves, thus leading to an almost in-phase variation of the MOC transport over the subtropical to subpolar North Atlantic. Citation: Getzlaff, J., C. W. Böning, C. Eden, and A. Biastoch (2005), Signal propagation related to the North Atlantic overturning, Geophys. Res. Lett., 32, L09602, doi:10.1029/2004GL021002.

\section{Introduction}

[2] The state of the North Atlantic Oscillation (NAO) imposes a strong constraint on the circulation of the North Atlantic: A number of studies show a connection between the rate of deep convection in the Labrador Sea and the winter time NAO-Index [e.g., Lazier, 1980; Dickson et al., 1996]. Model studies [e.g., Häkkinen, 1999; Eden and Willebrand, 2001] (hereinafter referred to as EW), point out the strong link between variability in the meridional overturning circulation (MOC), deep convection in the Labrador Sea and the driving agent, the NAO.

[3] Motivated by this link, and exploring the mechanism of MOC changes, Johnson and Marshall [2002] analyze the dynamical response of the MOC in an idealized, reduced gravity model following Kawase [1987]. They find that a convectively formed thickness anomaly drives a Kelvin wave along the western boundary, propagating to the equator in a few months, followed by an equatorial Kelvin wave to the eastern boundary and north- and southward Kelvin wave propagation along the east coast, radiating Rossby waves into the interior.

[4] The simulated propagation of dynamical signals of Johnson and Marshall [2002] is much faster than observational estimates from passive tracers [e.g., by Molinari et al., 1998] suggesting advective timescales of about 10 years for a convective signal in the Labrador Sea Water to reach
Bermuda. Döscher et al. [1994] describe the response of primitive equation models of the North Atlantic of different resolution to idealized changes in the thermohaline forcing in high latitudes. In agreement with the findings of Hsieh et al. [1983] of the dependence of boundary wave speeds on horizontal resolution in Arakawa-B-grid models, lower resolution experiments show slow signal propagation consistent with the advective time scale of Molinari et al. [1998]. The "eddy-permitting" cases exhibit a significantly faster response of the MOC in subtropical latitudes. These results suggest that for this class of ocean models the difference between the advection of water mass changes and dynamical changes in the baroclinic flow due to the propagation of fast boundary waves can only be modelled with increased horizontal resolution. In contrast, Dong and Sutton [2002] find a fast boundary wave response to a massive salinity perturbation in high latitudes even in a (coupled) coarse resolution model.

[5] The present paper expands on these previous studies by examining the response of the MOC to NAO related variations in deep convection. In contrast to previous, idealized studies we concentrate on setups closer to reality and available observations in two sets of experiments with North Atlantic models in realistic configurations: one, by forcing the models with heat fluxes based on reanalysis products and two, by examining the response to idealized, step-function heat flux changes related to NAO variations.

\section{The Model}

[6] We discuss experiments with OGCMs on an Arakawa $\mathrm{B}$-grid using the same forcing but different horizontal resolution, i.e., an "eddy-permitting" and a "non-eddyresolving" setup, both part of FLAME (Family of Linked Atlantic Model Experiments) as described by Beismann and Redler [2003], Böning et al. [2003], and EW. The horizontal resolution of the former is $\frac{1}{3}^{\circ}$ by $\frac{1}{3}^{\circ} \cos \Phi$ ( $\Phi$ denotes latitude) and the resolution of the latter is $\frac{4}{3}^{\circ}$ by $\frac{4}{3}^{\circ} \cos \Phi$. Both models span the Atlantic Ocean between $70^{\circ} \mathrm{N}$ and $20^{\circ} \mathrm{S}$ and share vertical resolution of 45 non-equidistant depth levels. More details can be found in work by Beismann and Redler [2003] and Böning et al. [2003]. The basic eddy-permitting experiment (HEAT 1/3) builds on a spin-up period of 25 years with climatological forcing. It uses forcing given by monthly mean NCEP/NCAR net heat flux anomalies [Kalnay et al., 1996] for the period 1958-1996 added to monthly climatological means based on ECMWF analysis [Barnier et al., 1995]. A companion case (CLIM) using climatological forcing, allows for the separation of internally and externally driven variability in the eddying model setup. Note that CLIM and HEAT 1/3 differ in their initial conditions. To analyze the effect of model resolution, we discuss a companion case with hori- 

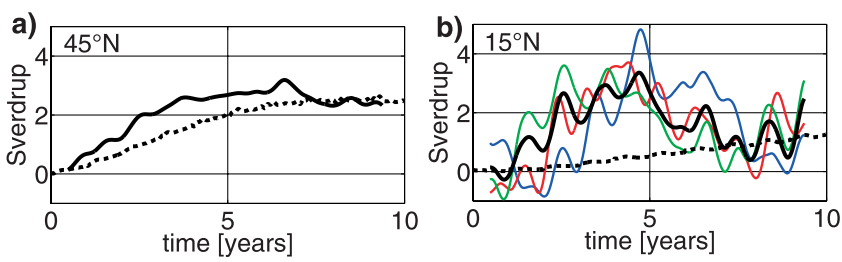

Figure 1. MOC anomaly $(S v)$ of RESP 4/3 (black dashed line) and RESP $1 / 3$ (black solid line) - a mean of three ensemble members - at (a) $45^{\circ} \mathrm{N}$ and (b) $15^{\circ} \mathrm{N}$. The thin coloured lines denote the response of each ensemble member. MOC is defined as the zonally integrated, southward-transport of deep water below $1500 \mathrm{~m}$. All time series in all figures are 2-year low-pass filtered to remove the seasonal cycle.

zontal resolution of $4 / 3^{\circ}$ (HEAT $4 / 3$, the same experiment as discussed by EW). To aid the interpretation of the MOC variability, we consider additional experiments focusing on the response to an idealized, step-function change in the heat flux (RESP 1/3 and RESP 4/3): at $t=0$, a permanent heat flux anomaly, corresponding to a NAO-index of 3 , is added to the climatological fluxes, as described in EW (their experiment NAO-heat). More specifically, RESP 1/3 represents an ensemble of three experiments with the eddypermitting model (differing in initial conditions) to separate the effect of internal fluctuations driven by hydrodynamical instabilities from externally driven changes. Note, that the wind stress is climatological and identical in all experiments. It is only the surface heat flux which is changed.

\section{Results}

[7] A prime effect of interannual variations in the buoyancy forcing over the subpolar North Atlantic related to the $\mathrm{NAO}$ is manifested in changes of deep water formation [e.g., Böning et al., 2003]. Corresponding to the variations in the convection intensity, there is also a clear response of the MOC in the OGCM: Figure 1a shows MOC anomalies at $45^{\circ} \mathrm{N}$ following increased heat losses due to a positive NAOphase for experiment RESP 4/3 and RESP 1/3. In both models the MOC strength follows the change in the buoyancy forcing with a lag of $2-3$ years. In the subtropics, the response shows a different behavior depending on resolution (Figure $1 b$ ). In contrast to the slow and monotonic increase of the MOC anomalies in RESP 4/3, RESP $1 / 3$ exhibits a much faster response during the first 2-3 years which we shall discuss now in more detail. Note that the fast increase of the MOC in the ensemble mean of the eddy-permitting experiments is also present in each ensemble member.

[8] Figure 2a shows the temporal evolution of the MOC anomalies in RESP $4 / 3$ between $10^{\circ} \mathrm{N}$ and $50^{\circ} \mathrm{N}$. The maximum amplitude of MOC anomalies is located between $43^{\circ} \mathrm{N}$ and $47^{\circ} \mathrm{N}$ initiated by the augmented deepwater formation in the Labrador Sea (EW). The southward propagation speed of the anomalous transport signal is varying with latitude. While it takes about 3-4 years to reach the latitude belt $45^{\circ} \mathrm{N}-40^{\circ} \mathrm{N}$ (corresponding to $\sim 0.6 \mathrm{~cm} / \mathrm{s}$ ), the speed becomes significantly larger south of $40^{\circ} \mathrm{N}$ (up to $\sim 3.5 \mathrm{~cm} / \mathrm{s}$ at subtropical latitudes). Because of the eddypermitting character of RESP $1 / 3$, these experiments include processes of internal instability which also produce inter- annual variability in the MOC (the rms amplitude of interannual transport variability in CLIM is about $0.15 \mathrm{~Sv}$ at $27^{\circ} \mathrm{N}$ ). In order to illustrate the internal variability and to separate it from the atmospherically driven signal, RESP $1 / 3$ is an ensemble of three experiments started in subsequent climatological years of the spinup. In all three cases the MOC responds with a lag of $\sim 2$ years to changes in the surface heat fluxes in the subpolar North Atlantic (Figure 2b).

[9] The major resolution dependence is found in the subtropics. In RESP $1 / 3$, it apparently takes only a few months up to half a year for the signal to reach $20^{\circ} \mathrm{N}$. As in RESP $4 / 3$, speeds are lower north of $40^{\circ} \mathrm{N}$ and faster in the subtropics where, however, speeds are now $\sim 20 \mathrm{~cm} / \mathrm{s}$ (between $20^{\circ} \mathrm{N}$ and $30^{\circ} \mathrm{N}$ ), consistent with Johnson and Marshall [2002] who find a propagation to the equator by boundary waves within a timescale of months. Note that south of $4^{\circ} \mathrm{N}$ a similar slowly propagating signal as in RESP $4 / 3$ still appears in RESP $1 / 3$, but now superimposed by the fast response. While RESP $4 / 3$ yields a continuous attenuation of the southward propagating signal, the MOC variability in RESP $1 / 3$ shows similar amplitudes in the subtropics as in the Labrador Sea.

[10] The response in the idealized model cases provides a basis for interpreting the MOC variability in HEAT 1/3 and HEAT $4 / 3$ and its relation to variations in the Labrador Sea Water formation and the NAO index. Figure 3a shows the interannual changes in the renewal rate of Labrador Sea Water (similar calculation as that of Böning et al. [2003]) together with changes of the winter NAO index [Hurrell, 1995]. Figure $3 \mathrm{~b}$ depicts the corresponding MOC anomalies. As expected from the idealized response cases, the southward propagation of the MOC anomalies strongly depends on horizontal resolution: HEAT 4/3 (Figure 3c) reveals a similar timescale of the signal propagation as before in RESP 4/3: a reaction of the MOC at $45^{\circ} \mathrm{N}$ to changes in the surface heat fluxes with a lag of $\sim 2$ years, a decreasing amplitude of the transport anomalies with latitude, and a rather slow southward propagation not much different from an advective timescale. The main features of the idealized response experiments are also reflected in the eddying model setup, HEAT 1/3. Changes in the MOC at

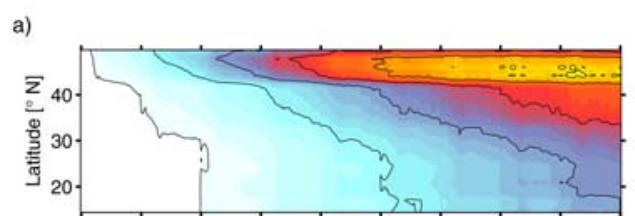

b)

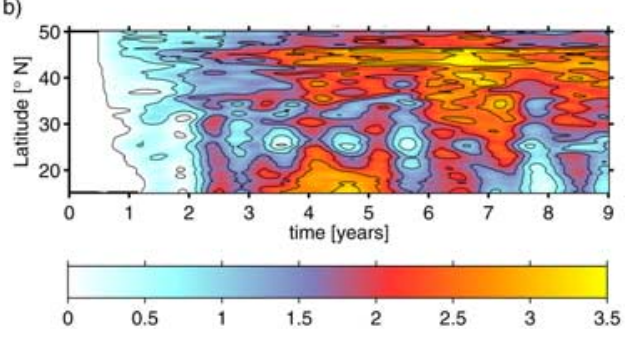

Figure 2. MOC anomaly $(S v)$ in the NAO response experiments (a) RESP $4 / 3$ and (b) RESP 1/3. The latter representing the mean of three ensemble members. 


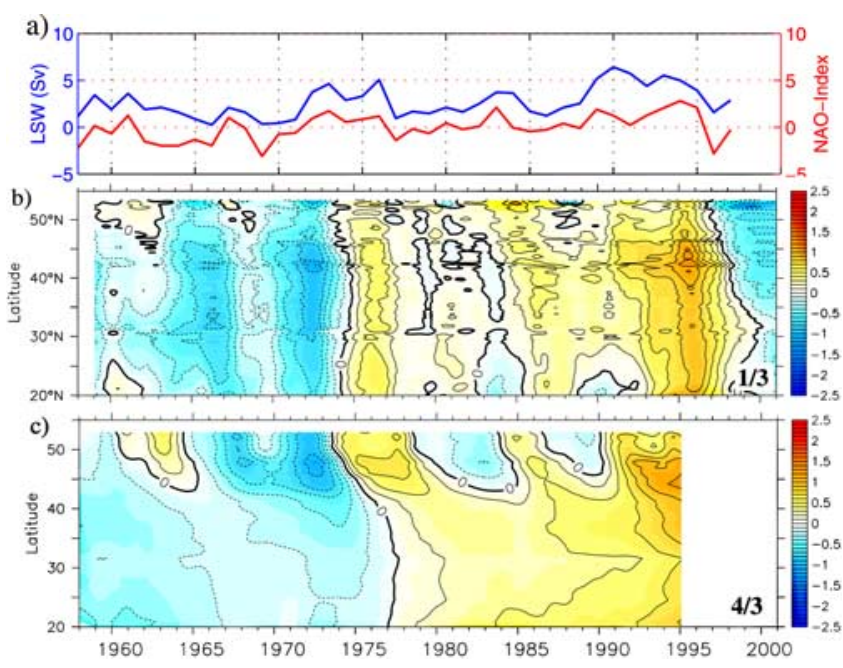

Figure 3. (a) Comparison between the rate of the Labrador Sea convection as given by the renewal of LSW (in $S v$, blue) and the NAO-Index (red). Below: MOC anomaly $(S v)$ of the model experiments forced by the NCEP-based heat flux for (b) HEAT 1/3 and (c) HEAT 4/3.

$45^{\circ} \mathrm{N}$ are related to surface heat loss changes with the same lag as in HEAT 4/3, while in the subtropics the southward propagating signal is much faster and less damped, occasionally even amplified as in RESP $1 / 3$.

[11] Given the irregular coastline and continental slopes represented in the model, the nature of the waves along the western boundary must differ from the baroclinic Kelvin waves governing the response in idealized model configurations [Greatbatch and Peterson, 1996; Winton, 1996] and should be interpreted in terms of the hybrid coastallytrapped waves discussed by Huthnance [1978]. Note that these hybrid waves propagate in the same direction as coastal Kelvin waves. Due to the strong variability of other origin (e.g., eddies), we are unable to identify coherent propagating structures along the coastline in the model results. However, a comparison between HEAT 1/3 and

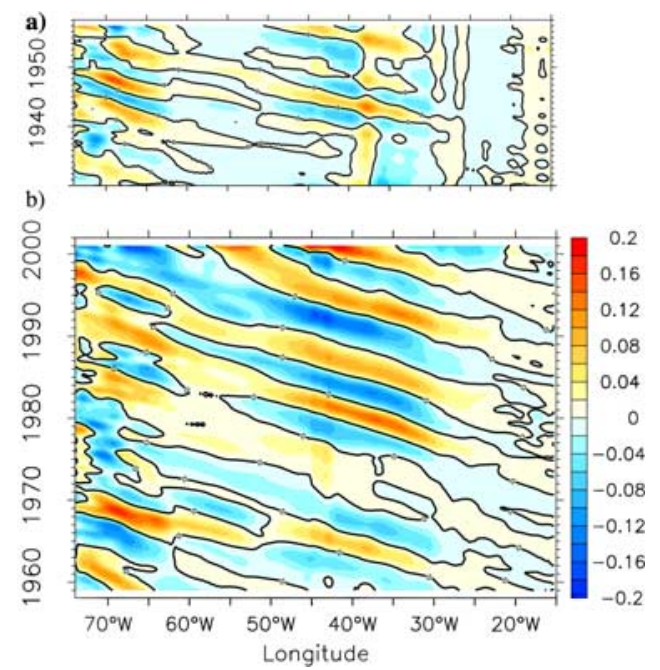

Figure 4. Meridional velocity anomalies (cm/s) in $2500 \mathrm{~m}$ depth along $27^{\circ} \mathrm{N}$, for (a) CLIM and (b) HEAT. the analogue experiment with climatological forcing (CLIM) gives evidence of a forced "Rossby wave-like" activity in the subtropics: Figure 4 shows meridional velocity anomalies in $2500 \mathrm{~m}$ depth along $27^{\circ} \mathrm{N}$ as a function of time and longitude for both experiments. Baroclinic Rossby-waves, apparently generated from near the Mid-Atlantic Ridge, are readily identified in CLIM (Figure $4 \mathrm{a})$ with wave lengths of $\mathrm{o}(100 \mathrm{~km})$, periods of about 5 years and westward phase propagation. In HEAT $1 / 3$ (Figure $4 b$ ), this wave-activity is amplified and furthermore originates in parts from the eastern side of the North Atlantic. The enhanced wave activity in HEAT 1/3 compared to CLIM is also seen in the variance of meridional velocity anomalies (Figure 5). Due to changes in the surface heat fluxes, there is an enhanced Rossby-wave signal coming along with the amplified MOC signal in the subtropical latitudes in this model.

\section{Conclusions and Discussion}

[12] We have presented results of experiments with OGCMs with realistic variability in surface heat fluxes, complemented by response experiments forced by an idealized, step-function change in the surface heat flux corresponding to a permanent NAO $3+$ pattern. North of the subpolar front, the response of the MOC to changes in the surface forcing related to a positive NAO is similar as described in EW, and appears only weakly dependent on model resolution. As discussed by Eden and Greatbatch [2003], the lag of 2-3 years of the MOC response due to the augmented convection changes in the Labrador Sea is associated in the $4 / 3^{\circ}$ model with a slow advective spreading of the newly formed water mass to the subpolar front.

[13] In contrast, south of the subpolar front we find a substantial difference in the meridional signal propagation of the MOC anomalies for different model resolutions. The timescale of the spreading in the $4 / 3^{\circ}$ model, in both the idealized response case (RESP 4/3) as well as in the realistically forced case (HEAT 4/3), is consistent with the float propagation shown by Lavender et al. [2000] for the subpolar North Atlantic and tracer observations at Bermuda [Molinariet al., 1998], i.e., of similar magnitude as the advective propagation of water parcels.

[14] The signal propagation in the experiments with the eddy-permitting version (RESP 1/3) shows a much larger propagation speed south of $48^{\circ} \mathrm{N}$ indicative of a baroclinic (Kelvin) wave response along the western boundary related to the fast part of the adjustment, consistent with Johnson and Marshall [2002] and Döscher et al. [1994]. The MOC

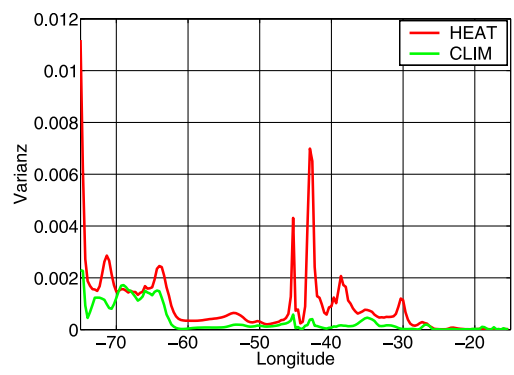

Figure 5. Variance of meridional velocity anomalies $\left(\mathrm{cm}^{2} / \mathrm{s}^{2}\right)$ in $2500 \mathrm{~m}$ depth along $27^{\circ} \mathrm{N}$, for CLIM and HEAT. 
changes in the eddy-permitting experiments, are amplified in the subtropics compared to the subpolar region. While the non-eddy resolving cases show a steady weakening of the propagating signal, the response behavior, as seen in the eddying model may be understood as a superposition of a fast, dynamical wave response, consistent with Kawase [1987] and Johnson and Marshall [2002] not connected to a transport of water mass properties, and a slower advective signal that do include a southward water mass transport and appears consistent to the observations by Molinari et al. [1998] and Lavender et al. [2000].

[15] As shown by Hsieh et al. [1983], any coarseresolution model formulated on an Arakawa B-grid not resolving the deformation radius, will encounter difficulties in properly representing Kelvin waves. Accordingly, in the $4 / 3^{\circ}$ model the fast dynamical signal is missing: since the first baroclinic Rossby-radius is smaller than the grid spacing anywhere in the $4 / 3^{\circ}$ model, boundary waves such as baroclinic Kelvin waves and coastal shelf waves are represented as viscous boundary waves with waves speeds much lower than baroclinic Kelvin wave speeds [Hsieh et al., 1983; Killworth, 1985], insufficient to introduce a faster adjustment timescale. Since the $1 / 3^{\circ}$ model is not eddyresolving north of the subpolar front, we may expect a fast wave-like response, and thus a faster dynamical adjustment also in the subpolar North Atlantic, to emerge going to higher resolution than $1 / 3^{\circ}$.

[16] The finding of [Dong and Sutton, 2002] of a fast boundary wave response in the North Atlantic with a time scale of months in a coarse resolution (B-grid) model very similar to our coarse model, appears difficult to reconcile in the light of the present results and those of Hsieh et al. [1983] and Killworth [1985]. The difference in time scales might, however, be related to the nature of the different forcing changes applied. Dong and Sutton [2002] introduce instantaneously a massive salinity perturbation at high latitudes that might lead to a different dynamical regime compared to the response to surface flux forced experiments, as considered here.

[17] We found forced Rossby-wave activity in the subtropics of the eddying model. It is appealing to relate this activity with Kawase's scenario of Rossby waves radiating from the eastern boundary during the adjustment process to high latitude forcing changes. However, note that such a signal would be characterized by wavelengths and periods much larger than the "forced Rossby-wave like" signal as seen in the eddying model. We might speculate that the model results suggest an interaction between the forced large scale circulation change and internal mesoscale, baroclinic variability generated at the MAR, since Rossbywave activity is present also in experiment CLIM, although weaker in amplitude and amplified in HEAT 1/3. Note that such a signal should have considerable effects on the detectability of low-frequency changes in the MOC from observations as e.g., boundary current moorings.
[18] Acknowledgments. Financial support was received through the BMBF as part of the DEKLIM program. The model integrations have been performed at the German high performance computing centres HLRS, Stuttgart and DKRZ, Hamburg. The authors gratefully acknowledge the efforts of the Kiel FLAME group, and of R. Redler (C\&C Research Laboratories, NEC Europe Ltd.) and J.-O. Beismann (NEC HPCE) in contributing to the model developments and simulations used for the present study.

\section{References}

Barnier, B., L. Siefridt, and P. Marchesiello (1995), Thermal forcing for a global ocean circulation model from a three-year climatology of ECMWF analyses, J. Mar. Syst., 6, 363-380.

Beismann, J.-O., and R. Redler (2003), Model simulations of CFC uptake in North Atlantic Deep Water: Effects of parameterizations and grid resolution, J. Geophys. Res., 108(C5), 3159, doi:10.1029/2001JC001253.

Böning, C. W., M. Rhein, J. Dengg, and C. Dorow (2003), Modeling CFC inventories and formation rates of Labrador Sea Water, Geophys. Res. Lett., 30(2), 1050, doi:10.1029/2002GL014855.

Dickson, R. R., J. Lazier, J. Meincke, P. Rhines, and J. Swift (1996), Longterm coordinated changes in the convective activity of the North Atlantic, Prog. Oceanogr., 38, 214-295.

Dong, B.-W., and R. T. Sutton (2002), Adjustment of the coupled oceanatmosphere system to a sudden change in the thermohaline circulation, Geophys. Res. Lett., 29(15), 1728, doi:10.1029/2002GL015229.

Döscher, R., C. W. Böning, and P. Hermann (1994), Response of circulation and heat transport in the North Atlantic to changes in the thermohaline forcing in northern latitudes: A model study, J. Phys. Oceanogr., 24, $2306-2320$

Eden, C., and R. J. Greatbatch (2003), A damped oscillation in the North Atlantic climate system, J. Clim., 16, 4043-4060.

Eden, C., and J. Willebrand (2001), Mechanism of interannual to decadal variability of the North Atlantic circulation, J. Clim., 14, 2266-2280.

Greatbatch, R. J., and K. A. Peterson (1996), Interdecadal variability and oceanic thermohaline adjustment, J. Geophys. Res., 101, 20,467-20,482.

Häkkinen, S. (1999), Variability of the simulated meridional heat transport in the North Atlantic for the period 1951-1993, J. Geophys. Res., 104, 10,991-11,007.

Hsieh, W. W., M. K. Davey, and R. C. Wajsowicz (1983), The free Kelvin wave in finite-difference numerical models, J. Phys. Oceanogr., 13, $1383-1397$.

Hurrell, J. W. (1995), Decadal trends in the North Atlantic Oscillation: Regional temperatures and precipitation, Science, 269, 668-676.

Huthnance, J. (1978), On coastal trapped waves: Analysis and numerical calculation by inverse iteration, J. Phys. Oceanogr., 8, 74-92.

Johnson, H. L., and D. P. Marshall (2002), A theory for the surface Atlantic response to thermohaline variability, J. Phys. Oceanogr., 32, 1121-1132.

Kalnay, E., et al. (1996), The NCEP/NCAR 40-year reanalysis project, Bull. Am. Meteorol. Soc., 77, 437-471.

Kawase, M. (1987), Establishment of deep ocean circulation driven by deep-water production, J. Phys. Oceanogr., 17, 2294-2317.

Killworth, P. D. (1985), A two-level wind and buoyancy driven thermocline model, J. Phys. Oceanogr., 15, 1414-1432.

Lavender, K. L., R. E. Davis, and W. B. Owens (2000), Mid-depth recirculation observed on the interior Labrador and Irminger seas by direct velocity measurements, Nature, 407, 66-69.

Lazier, J. R. N. (1980), Oceanic conditions at ocean weather ship Bravo, 1964-1974, Atmos. Ocean, 18, 227-238.

Molinari, R. L., R. A. Fine, W. D. Wilson, J. Abell, M. McCartney, and R. Curry (1998), The arrival of recently formed Labrador Sea water in the Deep Western Boundary Current at $26^{\circ} \mathrm{N}$, Geophys. Res. Lett., 25(13), $2249-2252$.

Winton, M. (1996), The role of horizontal boundaries in parameter sensitivity and decadal-scale variability of coarse-resolution ocean general circulation models, J. Phys. Oceanogr., 26, 289-304.

A. Biastoch, C. W. Böning, C. Eden, and J. Getzlaff, IFM-GEOMAR, Dusternbrooker Weg 20, D-24105 Kiel, Germany. (jfidler@ifm-geomar.de) 